\title{
Blood Culture Profile and Antimicrobial Resistance Pattern: A Study in Intensive Care Unit (ICU) Dhaka Shishu (Children) Hospital, Dhaka, Bangladesh
}

\author{
Md. Shafiul Hoque ${ }^{1 *}$, Probir Kumar Sarkar ${ }^{2}$, A.S.M. Nawshad Uddin Ahmed ${ }^{3}$
}

${ }^{1}$ Associate Professor of Paediatrics, MD, Bangladesh Institute of Child Health, Dhaka Shishu (Children) Hospital, Dhaka 1207, B angladesh

${ }^{2}$ Associate Professor of Paediatrics, FCPS, Bangladesh Institute of Child Health, Dhaka Shishu (Children) Hospital, Dhaka 1207, Bangladesh

${ }^{3}$ Professor of Paediatrics, FCPS, Bangladesh Institute of Child Health, Dhaka Shishu (Children) Hospital, Dhaka 1207, Bangladesh

DOI: $10.36347 /$ sjams.2020.v08i12.018

| Received: 02.12.2020 | Accepted: 12.12.2020 | Published: 14.12.2020

*Corresponding author: Md. Shafiul Hoque

Abstract

Original Research Article

\begin{abstract}
Background: Antimicrobial resistance is one of the major public health emergencies worldwide, and this trend didn't spare developing countries like Bangladesh. Objective: To Evaluate The Blood Culture Profile And Antimicrobial Resistance Pattern: A Study In Intensive Care Unit (ICU) Dhaka Shishu (Children) Hospital, Dhaka, Bangladesh. Methods: A hospital based observational study was conducted from April 2018 to May 2019 in Dhaka Shishu (Children) Hospital, Dhaka, Bangladesh. A total of 303 neonates with clinical sepsis were included. Collected data were entered into EPI-INFO version 6.04(CDC, Atlanta, GA) for cleanup; and then exported to SPSS version 21.0 for further analysis. Frequencies and proportion were used to describe the study population in relation to relevant variables. Results: Bacterial growth was detected in 88 (29.4\%) of blood cultures. Predominantly isolated bacteria were coagulase negative staphylococci (CoNS) 22 (25\%), Escherichia coli (E.Coli) 18 (20.5\%) and Staphylococcus aureus $16(18 \%)$. Resistance rates of S. aureus and CoNS against Ampicillin were $11(69 \%)$ and $20(91 \%)$ respectively. The resistance rate of E. coli against Ampicillin and Gentamycin were $12(66.7 \%)$ and $10(55.6 \%)$ while Klebsiella spp. resistance rate gets much higher against these two first line antibiotics [10 (91\%) and 9 (82\%) respectively]. Similarly, both Gram positive and Gram negative bacteria isolates were also highly resistant to third generation Cephalosporins, and 63 (72\%) isolated bacteria showed multidrug-resistance. However; Gram-positive bacteria isolates had better susceptibility patterns to third line antibiotics like Clindamycin, Vancomycin and Ciprofloxacin while Gram-negative isolates had a higher susceptibility to Ciprofloxacin and Amikacin. Conclusion: CoNS, S. aureus, E. coli and Klebsiella spp. were the leading bacterial causes of neonatal sepsis in our study. They were highly resistant to first- and second-line empiric antimicrobial treatment used at ICU (Intensive care unit), reducing the antimicrobial choices for management of neonatal sepsis. Fortunately, the mentioned isolated bacteria remained susceptible to third line antibiotics used to treat neonatal sepsis.

Keywords: Bacteria Isolates, Neonatal Sepsis, Antimicrobial Resistance.

Copyright (C) 2020 The Author(s): This is an open-access article distributed under the terms of the Creative Commons Attribution 4.0 International License (CC BY-NC 4.0) which permits unrestricted use, distribution, and reproduction in any medium for non-commercial use provided the original author and source are credited.
\end{abstract}

\section{INTRODUCTION}

Neonatal mortality contributes significantly to the infant mortality rate in developing countries, various conditions are responsible for neonatal mortality among which neonatal sepsis accounts for variable figures ranging from 26 to $50 \%$ [1-4]. Neonatal sepsis is defined as any sepsis diagnosed during the first 28 days of life and further sub classified as early onset neonatal sepsis if signs and symptoms of sepsis appeared within the first six days of life and classified as late onset sepsis if clinical features of sepsis are presented between 7 and 28 days of age [5]. Neonatal sepsis is mainly caused by different Gram-positive and Gramnegative bacteria and few cases by fungi like candida species. There is a significant geographical diversity of bacteria causing neonatal sepsis and the spectrum is constantly changing over time, even in the same place [5-7]. Antibiotic resistance has become a global threat. Reports of multidrug resistant bacteria causing neonatal sepsis in developing countries are increasing, particularly in intensive care units. The clinical signs and symptoms of neonatal sepsis are subtle and nonspecific, making early diagnosis difficult and leading to high rate of empiric antibiotic utilization which could contribute for the selection and spread of antimicrobial resistant strains of bacteria. Knowing the causative agents of neonatal sepsis and their antimicrobial sensitivity patterns could enable to choose appropriate therapy for neonatal sepsis. Targeted 
antibiotic therapy plays a significant role in reduction of antimicrobial resistance [5, 6]. As a sample, 1-2 $\mathrm{ml}$ of blood was withdrawn by a sterile disposable syringe with butterfly needle from a peripheral vein after cleaning the site with povidone iodine and chlorhexidane. The blood culture medium was aseptically inoculated and aerobically incubated at $37^{\circ} \mathrm{C}$ ( $20 \mathrm{ml}$ of Trypticase Soya Broth was used). Spectrum of organisms causing NS changes from region to region, center to center and also with change of time. Reports of epidemiological data from developing countries show important differences in bacterial pattern from that of developed countries [29].

\section{Methods And Materials}

A hospital based observational study was conducted from April 2018 to May 2019 at Dhaka Shishu (Children) Hospital, Dhaka, Bangladesh. The intensive care unit (ICU) is one of the wards with the highest performance of the hospital with the admission of close to 1200 neonates per year. Microbiology, hematology and biochemistry diagnostic laboratory services are available round the clock. Sample size was calculated based on prevalence reports of neonatal sepsis from different studies ranging from 20 to $40 \%$ [1, $8-10]$. By applying single population proportion and allowing $5 \%$ margin of error (d), with $95 \% \mathrm{CI}(\mathrm{z} \alpha / 2=$ $1.96) ; \mathrm{n}=(\mathrm{Za} / 2)^{2} \mathrm{P}(1-\mathrm{P}) / \mathrm{d}^{2}=(1.96)^{2} 0.3\left(0.7 /(0.05)^{2}=\right.$ 322. During the study period a total of 901 neonates were admitted to ICU from which the study participants were selected based. Neonates meeting the inclusion criteria but being too critically ill to undergo the necessary laboratory evaluation and other procedures were excluded. Accordingly, data of 19 neonates were excluded and a total 303 study subjects were analyzed.

\section{Operational Definition}

a) Early onset sepsis (EONS): Sepsis diagnosed in the first six days of life.

b) Late onset sepsis (LONS): Sepsis diagnosed between ages of 7 to 28 days of life.

c) Premature rupture of membrane (PROM): Rupture of membrane before onset of labor.

d) Prolonged premature rupture of membrane (PROM):PROM lasting for more than $18 \mathrm{~h}$

e) Prolonged labor: Total duration of labor for more than $24 \mathrm{~h}$.

f) Low Apgar score: Apgar score less than seven.

g) First line antibiotics: Ampicillin and Gentamycin.

h) Second line antibiotics: Third generation Cephalosporins.

i) Third line antibiotics: Vancomycin, Amikacin and Ciprofloxacin.

A standardized questionnaire was prepared by reviewing relevant literatures and neonatology text books and translated to local language to capture demographic data, risk factors and clinical features of sepsis. After the neonates were enrolled in the study, the mothers were interviewed at a convenient, comfortable and confidential area. Blood cultures are the gold standard test for the diagnosis of blood stream infection and should be performed in all cases of suspected sepsis prior to administering antibiotics. Accordingly, blood cultures were taken of neonates with clinical diagnosis of. Under preferably aseptic techniques a blood sample was collected by trained laboratory technicians: The laboratory technicians wore sterile gloves during the procedure and prepared a patch of skin approximately 5 $\mathrm{cm}$ in diameter over the proposed site of venipuncture. This area was cleansed thoroughly with $70 \%$ isopropyl alcohol, followed by povidone iodine, and followed again by alcohol. The skin was allowed to dry for at least $1 \mathrm{~min}$ before venipuncture. One $\mathrm{ml}$ sample of blood was drawn from a fresh venipuncture site and added to a bottle containing $5-10 \mathrm{~mL}$ of blood agar culture media. The blood cultures were incubated aerobic-ally at $37^{\circ} \mathrm{C}$ and observed daily for consecutive three days for preliminary results by checking the presence of one of the following findings on culture media: hemolysis, air bubbles (gas production) and coagulation of broth [12]. At the same time, subcultures were made during three successive days on enriched and selective media including blood agar, chocolate agar, and MacConkey agar and mannitol salt agar plates and examined for growth after $24-48 \mathrm{~h}$ of incubation. Showing no growth on the 7 th day, blood cultures were reported as sterile. Isolated bacteria were identified using different standard techniques like Gram stain reaction, biochemical reaction properties (Lactase, Catalase, Indolase), morphological and colony characteristics [12]. Antimicrobial sensitivity testing was performed by Kirby Bauer diffusion method using Mueller Hinton agar with incubation of $24 \mathrm{~h}$ at $37{ }^{\circ} \mathrm{C}$ according to Clinical Laboratory Standard Institute standards (CLSI) [8].

\section{Data Collected}

Testing was done for antibiotics used for first, second and third line treatment in neonatal sepsis at ATRH [8]. The following antibiotic discs were used: Ampicillin $(10 \mu \mathrm{g})$, Cloxacillin $(5 \mu \mathrm{g})$, Gentamicin (10 $\mu \mathrm{g})$, Amikacin $(30 \mu \mathrm{g})$, Ceftriaxone $(30 \mu \mathrm{g})$, Ciprofloxacin $(5 \mu \mathrm{g})$, Vancomycin $(30 \mu \mathrm{g})$.

\section{Data Analysis}

Data was entered into EPI-INFO version 6.04(CDC, Atlanta, GA) for cleanup and anthropometric interpretation; and then, data were exported to SPSS version 21 edition for further analysis. Frequencies, proportion and summary statistics were used to describe the study population in relation to relevant variables. P-values $<0.05$ were considered statistically significant.

\section{RESULTS}

A total of 303 neonates were admitted with the diagnosis of clinical sepsis of which 88 (29.4\%) were culture proven. From those with culture confirmed 
neonatal sepsis, male constituted for $52(59.1 \%)$ while females were $36(40.9 \%)$. When looking at bacteria isolates disaggregated to the age of neonates at presentation, $37(42.4 \%)$ bacteria isolates were identified from EONS while $54(61.2 \%)$ from LONS which is statistically significant $(\mathrm{p}=0.001)$. Neonates born to mother who took antibiotic during labor and delivery were having two-fold reduced risk of acquiring EONS compared to LONS [AOR 2.02 (95\% CI 1.17$3.50, \mathrm{p}=0.011]$. Eight $(9 \%)$ neonates with culture proven sepsis were born at home while 80 (91\%) were born at a health institution (health center or hospital). Babies with low 5th minute Apgar score had high associated with culture confirmed neonatal sepsis [AOR 2.10 (95\% CI 1.18-3.73, p = 0.001]. Gram-positive bacteria accounted for $49(55.7 \%)$ while the remaining $39(44.3 \%)$ were Gram-negative bacteria. Most Grampositive [33 (67.3\%)] bacteria were reported from neonates with clinical diagnosis of LONS at the time of presentation $(\mathrm{p}=0.001)$. About $23(63.3 \%)$ of bacterial isolates from EONS were Gram-negative while close to two third of identified bacteria from LONS were Grampositive [Table 1]. When disaggregating to specific bacteria pathogen; CoNS $(22,25 \%)$ and E. coli $(18,20.5 \%)$ were by far the leading causes of neonatal sepsis in our study.

Table-1: Cross tabulation showing distribution of isolated bacteria based on the age at time of sepsis diagnosis $(\mathrm{N}=303)$

\begin{tabular}{|l|l|l|l|}
\hline Isolated bacteria & EONS, n (\%) & LONS, n (\%) & p value \\
\hline CoNS1 & $5(22.7)$ & $17(77.3)$ & 0.001 \\
\hline E. coli & $12(66.7)$ & $6(33.3)$ & \\
\hline S. aureus2 & $3(18.7)$ & $13(81.3)$ & \\
\hline Klebsiella spp. & $4(36.4)$ & $7(63.6)$ & \\
\hline Enterobacter spp. & $2(28.6)$ & $5(71.4)$ & \\
\hline Enterococcus spp. & $3(50)$ & $2(60)$ & \\
\hline Citrobacter spp. & $1(33.3)$ & $2(40)$ & \\
\hline others ${ }^{\text {a }}$ & $3(60)$ & \\
\hline $\begin{array}{l}\text { CoNS1, Coagulase negative staphylococcus S. aureus2, staphylococcus aureus, } \\
\text { a Include: Streptococcus pneumoniae, Listeria monocytogenes and candida. Acenetobacter, Pseudomona }\end{array}$ \\
\hline
\end{tabular}

\section{Sensitivity patterns of isolated bacteria Gram-positive bacteria}

Most Gram-positive bacteria isolates were from LONS, possibly being hospital acquired infections. These bacteria were highly resistant to first line and second line antibiotics (Ampicillin and Gentamycin) and third generation cephalosporins used at ICU. The resistance rates of CoNS, S. aureus and Enterococcus against Ampicillin were 20(91\%), $11(69 \%)$ and $2(33.3 \%)$ respectively (Table-3). Similarly, the resistance rates of these three organisms to Gentamycin were $14(63.6 \%), 9(56.6 \%)$ and $4(66.7 \%)$ respectively. Identified Gram positive bacteria were also highly resistant to third generation cephalosporins with a cumulative resistance rate against Ceftriaxone, Ceftazidime and Cefotaxime being 29(60\%), 23(47\%), and $31(64 \%)$ respectively. Isolated Gram-positive bacteria showed better susceptibility patterns for Vancomycin, Clindamycin, Ciprofloxacin and Chloramphenicol (Table-2). Significant methicillin resistance rate was detected in Staphylococcus aureus and CoNS which were $11(69 \%)$ and $22(100 \%)$ respectively.

Table-2: Antimicrobial resistance patterns of isolated Gram-positive bacteria; at ICU, ATRH. (N=303)

\begin{tabular}{|l|l|l|l|}
\hline & CoNS & S. aureus & Enterococcus spp. \\
\hline & $\mathrm{N}(\%)$ & $\mathrm{N}(\%)$ & $\mathrm{N}(\%)$ \\
\hline Ampicillin & $20(91)$ & $11(69)$ & $2(33.3)$ \\
\hline Gentamycin & $14(63.6)$ & $9(56)$ & $4(66.7)$ \\
\hline Ceftriaxone & $16(73)$ & $9(56)$ & $3(50)$ \\
\hline Ciprofloxacin & $8(36.2)$ & $4(25)$ & $1(16.7)$ \\
\hline Cotrimoxazole & $16(73)$ & $11(69)$ & $4(66.7)$ \\
\hline Vancomycin & $6(27.3)$ & $3(19)$ & $1(16.7)$ \\
\hline Chloramphenicol & $10(45.5)$ & $6(37)$ & $2(33.3)$ \\
\hline Clindamycin & $4(18)$ & $3(12)$ & $2(33.3)$ \\
\hline Erythromycin & $15(68)$ & $9(56)$ & $5(66.7)$ \\
\hline Cloxacillin & $22(100)$ & $11(69)$ & $\mathrm{NT}^{\mathrm{a}}$ \\
\hline
\end{tabular}

\section{Gram-Negative Bacteria}

In the current study, isolated Gram-negative bacteria were also highly resistant to commonly used empiric antibiotics at our ICU (Table-3). E. coli and
Klebsiella species were extremely resistant to Ampicillin [12(66.7\%) and 10(91\%) respectively]. Similarly, these bacteria were also highly resistant against Gentamycin $[11(55.6 \%)$ and $9(82 \%)$ 
respectively]. E. coli and Klebsiella resistance rates against Cefotaxime, one of the commonly used third generation Cephalosporin at our ICU were also high. Chloramphenicol, Ciprofloxacin and Amikacin showed more effectiveness against identified Gram-negative bacteria. Multidrug resistant (MDR) bacterial isolates.
Most bacterial isolates from blood culture were found to be multidrug resistant, mainly against first and second line antibiotics. About two third of E. coli, 10(91\%) of Klebsiella spp., 6(85.7\%) of Enterobacterspp and $3(50 \%)$ of Entero-coccus spp. were reported to be MDR.

Table-3: Antimicrobial resistance patterns against selected gram-negative bacteria; at ICU, ATRH (N=303)

\begin{tabular}{|l|l|l|l|l|}
\hline & E.coli & Klebsiellaspp & Citrobacter & Enterobacterspp \\
\hline & $\mathrm{N}(\%)$ & $\mathrm{N}(\%)$ & $\mathrm{N}(\%)$ & $\mathrm{N}(\%)$ \\
\hline Ampicillin & $12(66.7)$ & $10(91)$ & $\mathrm{NT}^{\mathrm{a}}$ & $6(85.5)$ \\
\hline Gentamicin & $10(55.6)$ & $9(82)$ & $2(66.7)$ & $6(85.7)$ \\
\hline Cefotaxime & $11(61.1)$ & $9(82)$ & $1(33.3)$ & $3(43)$ \\
\hline Ciprofloxacin & $5(22.3)$ & $3(27)$ & $1(33.3)$ & $2(28.6)$ \\
\hline Cotrimoxazole & $11(63.6)$ & $8(73)$ & $\mathrm{NT}^{\mathrm{a}}$ & $5(71.4)$ \\
\hline Chloramphenicol & $8(50)$ & $6(56)$ & $\mathrm{NT}^{\mathrm{a}}$ & $\mathrm{NT}^{\mathrm{a}}$ \\
\hline Amikacin & $4(22.2)$ & $4(36)$ & $\mathrm{NT}^{\mathrm{a}}$ & $3(43)$ \\
\hline Erythromycin & $12(66.7)$ & $9(72)$ & $\mathrm{NT}^{\mathrm{a}}$ & $\mathrm{NT}^{\mathrm{a}}$ \\
\hline \multicolumn{7}{|l|}{$\mathrm{b}{ }^{\mathrm{a}}$ Not tested Psedomonas, Acenetobacter } \\
\hline
\end{tabular}

\section{DiscuSSION}

In the current study, about one third of the total neonatal admissions were due to clinical sepsis with or without bacterial growth in blood cultures still remains the most important cause of neonatal morbidity. This finding is consistent with reports from other developing countries [1-3]. The rate of blood culture confirmed neonatal sepsis were significantly lower among neonates with EONS than with LONS. One possible explanation for the difference in blood culture results could be because of the routine utilization of antibiotics during obstetric care which might affect the blood culture yield of the neonates as there is significant transplacental transfer of these antibiotics to the fetus. Gram-positive bacteria were the most commonly isolated organisms causing neonatal sepsis in this finding which is in congruent with study reports from Egypt, Uganda and other developing countries [3, 4, 9, $13,14]$. Babies with low $5^{\text {th }}$ minutes Apgar score had high risk of developing culture-confirmed Grampositive neonatal sepsis which could be explained by the fact that most neonates with low Apgar score might undergo extensive manipulation and resuscitation predisposing them for possible invasive colonization with Gram-positive bacteria. Also, this finding is in accordance with studies from Ethiopia and Tanzania [1, 2]. The majority of the isolates were found in LONS, being previously described in a study from TanzaniaMuhimbili which reported S. aureus as the leading cause of neonatal sepsis $[1,15]$. Similar findings were reported from Bangladesh, Egypt, Tanzania, Uganda, Ethiopia, and other developing countries which showed Gram-positive bacteria as predominant isolates causing neonatal sepsis $[6,7,11,16-18]$. Guidelines on neonatal sepsis management in most centers [7, 19] recommend Ampicillin and Gentamycin as first line empiric therapy. Unfortunately, most identified bacteria were highly resistant in this current report. Egypt and India $[6,7]$ showed high resistance rates of isolated bacteria against Ampicillin (85-95\%) and Gentamycin (57.3$72 \%)$. The demonstrated high rate of antimicrobial resistance (AMR) could be indicating overutilization of the named drugs as empiric treatment for most other common neonatal problems which were not actually infectious in origin. Additionally, most neonates with culture proven bacteremia were born at a health institution where most neonatal sepsis is arising from hospital acquired infections. Resistance rates of isolated Gram-positive bacteria against third generation Cephalosporines were also high in our study which is consistent with studies from Nigeria, Tanzania, Georgia, Iran and other developing countries [11, 12, 15, 17, 19-23]. Methicillin resistant S. aureus (MRSA) and MDR against both, Gram-positive and Gramnegative bacteria isolates were very high in our study finding which is in agreement with most studies [1, 2, 17, 18, 24]. Our study demonstrated a better susceptibility of isolated Gram-positive bacteria against Vancomycin, Clindamycin and Ciprofloxacin, which is also supported by the study from Bangladesh and other reports $[1-4,9,13,15,17,24]$. Gram-negative isolates were $22(70.97 \%)$ and gram-positive 9 (29.03\%). Klebsiella pneumoniae was the most common (41.9\%), followed by staphylococcus aureus (29\%) and E. coli (19.4\%) among the isolates. All the three common isolates showed $100 \%$ resistance to ampicillin and very poor sensitivity to gentamicin [29]. This could be explained by less utilization of these antibiotics for two reasons: First, the antibiotics are used as third line options indicating less utilizations of these agents at ICU. Second, Ciprofloxacin is not validated to use among younger children unless benefit risk analysis warrants its utilization and, Amikacin is not easily accessible in most centers showing its lower rate of utilization making most isolated bacteria better susceptible to these two antibiotics. Still about one fifth of isolated S. aureus were found to be resistant for vancomycin which is in contrary with study findings from Vietnam and Egypt showed no resistance strains of $\mathrm{S}$. aureus against 
Vancomycin [7, 21]. This could be explained by increasing trends of utilization of this antibiotic as third line because most first-line and second-line antimicrobial agents have been failing which is in line to other study findings [5, 10, 11, 21, 22, 25-27], E. coli and Klebsiella spp. the two predominant Gram-negative bacteria isolates in our study, were highly resistant to Ampicillin, Gentamycin and third generation Cephalosporines. Better susceptibility of E. coli and Klebsiella spp. for Ciprofloxacin and Amikacin were reported in our study which have been also demonstrated in other study findings $[11,16]$. These two drugs could be a potential antibiotic of choice for empiric treatment of neonatal sepsis in the future.

\section{CONCLUSION}

CoNS, S. aureus, E. coli and Klebsiella spp. were the leading causes of neonatal sepsis in our study finding. These bacteria isolates were highly resistant to first- and second-line empiric antimicrobials used at ICU contracting antimicrobial choices for management of neonatal sepsis. Third line antibiotics relatively effective against isolated bacteria. Utilization rate of antibiotics is the most important contributory factor for the development of AMR and continuous surveillance is needed in order to keep national guidelines on antimicrobial therapy updated.

\section{REFERENCES}

1. Mhada TV, Fredrick F, Matee MI, Massawe A. Neonatal sepsis at Muhimbili National Hospital, Dar es Salaam, Tanzania; aetiology, antimicrobial sensitivity pattern and clinical outcome. BMC public health. 2012 Dec 1;12(1):904:2-5.

2. Moges F, Eshetie S, Yeshitela B, Abate E. Bacterial etiologic agents causing neonatal sepsis and associated risk factors in Gondar, Northwest Ethiopia. BMC pediatrics. 2017 Dec 1;17(1):137.

3. Tilahun T, Seida M, Yibeltal T. Clinical outcome and risk factors of neonatal sepsis among neonates in Felege Hiwot referral hospital, Bahir Dar, Amhara regional state North West Ethiopia. BMC Res Notes. 2017;10(265):1-6.

4. Alexandra YK, Do HTC, Cam NP. Neonatal bloodstream infections in aediatric hospital in Vietnam: a cohort study. J Tropical Pediatrics, 2013; 59(6):1-7.

5. Vergnano S, Sharland $M$, Kazembe $P$, Mwansambo C, Heath PT. Neonatal sepsis: an international perspective. Archives of Disease in Childhood-Fetal and Neonatal Edition. 2005 May 1;90(3):F220-F224.

6. Bambala PZ, Vishnu B, Belgode NH. Neonatal sepsis in a tertiary Care Hospital in South India: bacteriological Profile and antibiotic sensitivity pattern. Indian J Pediatr, 2010; 10(5):1-5.

7. Richard A. P and the committee on fetus and newborn. Management of Neonates with suspected or proven early-onset bacterial sepsis. AAP, 2012; 129(5):1006-12.

8. Federal Ministry of Health of Ethiopia. Neonatal Intensive Care Unit Manual, 2014:73.

9. Nino M, Ekaterina K, Maia B, et al. Etiology of neonatal blood stream infections in Tbilisi, republic of Georgia. International $\mathbf{J}$ of Infect Dis 2009; 13: 499-505.

10. Bhagyashri B, Clinical Profile SS. Risk factors in neonatal sepsis. Journal of Dental and Medical Sciences 2017; 16(12):75-9.

11. Barrow GI, Feltham RKA. Cowan and Steel's manual for identification of medical bacteria. 3rd ed. Cambridge: Cambridge University Press; 2003. p. $219-40$.

12. WHO. Neonatal Sepsis. AIIMS Protocol 2014:1-9.

13. Robert MK, Bonita FS, Joseph W. Nelson Textbook of Pediatrics. 20th ed. 1600 John F. Kennedy Blvd: Library of Congress Cataloging; 2016:909-25.

14. Afsharpaiman S, Torkaman M, Saburi A, Farzaampur A, Amirsalari S, Kavehmanesh Z. Trends in incidence of neonatal sepsis and antibiotic susceptibility of causative agents in two neonatal intensive care units in Tehran, IR Iran. Journal of clinical neonatology. 2012 Jul;1(3):124129.

15. Ramesh BY, Leslie ESL, Vandana KE. Bacterial isolates of early-onset neonatal sepsis and their antibiotic susceptibility pattern between 1998 and 2004: an audit from a center in India. Ital J Pediatr. 2011; 37(32):1-5.

16. Clinical and Laboratory Standard Institute: Performance standards for antimicrobial disk susceptibility tests. Approved standard. In 11th edition document M02-A11. Wayne: Clinical and Laboratory Standards Institute; 2012:12-27.

17. Nyambura M, Heike C, Stephen EM. Antimicrobial resistance pattern: a report of microbiological cultures at a tertiary hospital in Tanzania. BMC Infect Dis. 2016; 16(756):1-6.

18. Mugalu J, Nakakeeto MK, Kiguli S, KadduMulindwa DH. Aetiology, risk factors and immediate outcome of bacteriologically confirmed neonatal septicaemia in Mulago hospital, Uganda. African health sciences. 2006 Sep 25;6(2):120-6.

19. Arowosegbe AO, Ojo DA, Dedeke IO, Shittu OB, Akingbade OA. Neonatal sepsis in a Nigerian Tertiary Hospital: Clinical features, clinical outcome, aetiology and antibiotic susceptibility pattern. Southern African Journal of Infectious Diseases. 2017 Oct 2;32(4):127-31.

20. Neema K, Erasmus K, Damas LM. Predictors of positive blood culture and deaths among neonates with suspected neonatal sepsis in a tertiary hospital, Mwanza- Tanzania. BMC Pediatr. 2010; 10(39):1-9.

21. Huynh BT, Padget M, Garin B, Herindrainy P, Kermorvant-Duchemin E, Watier L, Guillemot D, Delarocque-Astagneau E. Burden of bacterial 
resistance among neonatal infections in low income countries: how convincing is the epidemiological evidence?. BMC infectious diseases. 2015 Dec 1;15(1):127.

22. World Health Organization (WHO). Antimicrobial resistance: global report on surveillance. 2014 June: $10-20$.

23. Anita KMZ, Durrane T, Syed AA, Tauseef AK. Pathogens associated with sepsis in newborns and young infants in developing countries. Pediatr Infect Dis J. 2009; 28(1):1-4.

24. Shehab El-Din EM, El-Sokkary MM, Bassiouny MR, Hassan R. Epidemiology of neonatal sepsis and implicated pathogens: a study from Egypt. BioMed research international. 2015 Jun 4;2015;15(6):1-9.

25. Daynia EB, Trusha N, Charlotte S, Peter AC. Bacterial bloodstream infections in neonates in a developing country. ISRN Pediatrics, 2012; 2012:1-5.

26. Aishiya I, Asfiya F, Varsha AS, et al. Clinical and bacteriological profile of neonatal septicemia.
International J of Recent Scientific Research 2017; 8(11): 21465-7.

27. Seale AC, Blencowe H, Manu AA, Nair H, Bahl R, Qazi SA, Zaidi AK, Berkley JA, Cousens SN, Lawn JE. Estimates of possible severe bacterial infection in neonates in sub-Saharan Africa, south Asia, and Latin America for 2012: a systematic review and meta-analysis. The Lancet infectious diseases. 2014 Aug 1;14(8):731-41.

28. Eitan NB, Fortino S. The Latin America working group on bacterial resistance. Gram-negative infections in pediatric and neonatal intensive careunits of Latin America. J Infect Dev Ctries, 2014; 8(8):942-53.

29. Islam QR, Shahidullah M, Islam MZ, Mridha MA, Akter S. Bacterial Profile of Neonatal Septicemia and Antibiotic Susceptibility Pattern of the Isolates in Tertiary Care Hospital, Dhaka, Bangladesh. Bangladesh Journal of Child Health. 2019 Apr 28;43(1):35-40. 